\title{
Intencionalidade Comunicativa e Atenção Conjunta: Uma Análise em Contextos Interativos Mãe-Bebê
}

\author{
Communicative Intentionality and Joint Attention: An Analysis \\ in the Context of Mother-Baby Interactions
}

\author{
Fabiola de Sousa Braz Aquino* \& Nádia Maria Ribeiro Salomão \\ Universidade Federal da Paraíba , João Pessoa, Brasil
}

\begin{abstract}
Resumo
O objetivo deste estudo foi analisar as manifestações de intencionalidade comunicativa em episódios interativos mãe-bebê, considerando-se as relações entre intencionalidade comunicativa, atenção conjunta e trocas intersubjetivas mãe-bebê. Participaram dessa pesquisa seis díades mãe-bebê aos seis, nove e doze meses do bebê, observadas em suas residências, numa situação de brincadeira livre, durante quarenta minutos em cada etapa. Através das análises das observações foram identificados marcos na trajetória evolutiva e diferentes configurações sociocomunicativas e de atenção conjunta nas díades. Verificou-se que as aquisições de comunicação intencional e os diferentes contextos de atenção conjunta redirecionaram o curso das interações, em cada idade. Este estudo contribui para a discussão relativa à cognição social infantil com ênfase nas relações entre atenção conjunta, comunicação intencional e aquisição da linguagem. Palavras-chave: Interação mãe-bebê; Intencionalidade comunicativa; Atenção conjunta.
\end{abstract}

\begin{abstract}
The purpose of this study was to analyze the manifestation of communicative intentionality in motherbaby interactive episodes considering the relations between communicative intentionality, joint attention and mother-baby inter-subjective exchanges. This research involved the participation of 6 mother-baby dyads. Babies were six, nine and twelve months old and were observed in their houses in a free play situation for forty minutes in each observation period. Landmarks of the evolutionary trajectory were identified through observations, making it possible to verify intra-individual and inter-individual changes regarding the abilities evidenced by the dyad. The acquisition of intentional communication and the different interactive contexts of joint attention redirected the course of the interactions in each observed period. This study contributes to the discussion on infant's social cognition in the first year of life emphasizing the relations among joint attention, intentional communication and language acquisition.

Keywords: Mother-baby interaction; Communicative intentionality; Joint attention.
\end{abstract}

A compreensão da habilidade de comunicação intencional em bebês no primeiro ano de vida tem sido alvo de indagações e debates de pesquisadores que estudam a cognição social infantil no primeiro ano vida (Bakeman \& Adamson, 1984; Bruner, 1975, 1980; Camaioni, Aureli, Bellagamba, \& Fogel, 2003; Tomasello, 1995).

Nas primeiras redes de interações estabelecidas entre bebês e adultos há uma gama de habilidades que dão suporte ao desenvolvimento de potencialidades tipicamente humanas, tal como a capacidade de apreender significados pelo compartilhar de atividades culturalmente construídas, essenciais para o desenvolvimento de habilidades sociocognitivas que têm seu ponto de partida na

* Endereço para correspondência: Universidade Federal da Paraíba, Departamento de Psicologia, Campus 1, Conjunto Castelo Branco I, João Pessoa, PB, Brasil, CEP 580oo-900. E-mails: fabiolabrazaquino@gmail.com e nmrs@uol.com.br infância (Bruner, 1980; Rochat, 2007; Vygotsky, 1932/ 1996).

Investiga-se, nesta área, o momento no qual os bebês conseguem se comunicar de forma intencional, bem como interpretar um comportamento do adulto, como intencional, o papel das primeiras interações mãe-bebê no surgimento dessa habilidade, a potencial relação entre contextos de atenção conjunta, comunicação intencional e aquisição da linguagem; e as contribuições de aspectos do desenvolvimento infantil (cognitivo, afetivo, motor) que podem estar diretamente relacionados à explicação da comunicação de natureza intencional (Brooks \& Meltzoff, 2008; Bruner, 1999; Dunham \& Moore, 1995; Hobson, 2007; Liszkowski, 2005; Striano \& Bertin, 2005).

Outros estudos verificaram a relação entre atenção conjunta e características específicas do input materno (Braz \& Salomão, 2002; Braz Aquino \& Salomão, 2005), e as diferentes configurações do tempo de atenção conjunta em interações mãe-bebê e mãe-criança, através de uma 
abordagem transversal (Santos \& Braz Aquino, 2003). Além disso, discute-se o desenvolvimento da habilidade de atenção compartilhada e suas implicações para a identificação precoce de distúrbios invasivos de desenvolvimento tal como o autismo (Bosa, 2002; Lampreia, 2007).

Autores como Tomasello $(1995,1999,2003)$ asseveram a existência de um tipo especial de intencionalidade, que emerge como uma espécie de "revolução" aos nove meses, que ele designou como intenções comunicativas infantis. Para o autor, a aquisição de uma forma de comunicação intencional é fundamental para uma configuração mais complexa de comportamento que se refere à compreensão dos outros como seres intencionais. Isto porque, para ele, entre os nove e doze meses surge um conjunto de habilidades sociocognitivas triádicas, denominadas atenção conjunta, as quais representariam um evento decisivo na maneira como as crianças se relacionam com seu mundo.

No presente artigo, entende-se, tal como Rochat (2007), que a habilidade de comunicação intencional desenvolve-se por meio de trocas recíprocas, do espelhamento afetivo e da imitação mútua, os quais possibilitam ao bebê uma oportunidade única para estabelecer distinções entre o "eu" e a perspectiva do outro. Na visão do autor, o desenvolvimento de ações intencionais nos bebês resultaria da maneira única e tipicamente humana de comunicação recíproca e intencional entre os bebês e seus cuidadores, desde períodos iniciais da vida infantil. Considera-se ainda, partindo dos apontamentos de Rivero (2003), que a comunicação intencional nos bebês é uma habilidade co-construída num contexto social e relacional desde as primeiras trocas sociais estabelecidas entre o bebê e $o$ adulto.

Os questionamentos advindos dos diferentes pontos de vista (Brooks \& Meltzoff, 2008; Rochat, 2007; Sabbagh \& Baldwin, 2007; Tomasello, 2003) formulados acerca do momento em que surge nos bebês a habilidade de intenção comunicativa ressaltam a pertinência de estudos que identifiquem, em contextos interativos mãe-bebê, as configurações e relações entre a comunicação intencional e a habilidade de atenção conjunta em bebês no primeiro ano da vida, principalmente pelo impacto que o interjogo dessas habilidades provoca no desenvolvimento infantil. Considera-se, ainda, que os diferentes pontos de vista adotados acerca do momento de emergência da habilidade de comunicação intencional estão relacionados às estratégias metodológicas e conceituais utilizadas para o estudo da referida temática.

O presente estudo buscou obter uma melhor compreensão das habilidades de comunicação intencional, por meio da análise de contextos interativos diádicos mãebebê em três momentos do primeiro ano de vida. Buscou-se especificamente identificar comportamentos nos bebês que demonstrassem sua capacidade de comunicar à mãe uma intenção em relação a algo ou alguém, e verificar as diferentes configurações da habilidade de atenção conjunta e comunicação intencional nos con- textos interativos em cada idade. Esse tipo de estudo torna-se relevante por apresentar dados empíricos concernentes à cognição social infantil, que na literatura nacional ainda se constituem escassos.

\section{Método}

O delineamento de pesquisa utilizado foi o longitudinal, o qual permite estabelecer a trajetória evolutiva de indivíduos, obter uma descrição detalhada do desenvolvimento da comunicação, bem como delinear a transição desse desenvolvimento numa estrutura de comunicação compartilhada e dos atos comunicativos, a partir de uma análise da dinâmica dessas interações. Este tipo de delineamento possibilita ao pesquisador o acesso tanto às mudanças intra-individuais quanto interindividuais referentes ao que se pretende investigar (Lavelli, Pantoja, Hsu, Messinger, \& Fogel, 2004).

\section{Participantes}

Participaram deste estudo seis díades mãe-bebê nas idades de seis, nove e doze meses. As mães tinham a idade média de 27,7 anos, sendo a idade mínima de 24 e a máxima de 30 anos. O nível de instrução das mães variou entre o superior incompleto e o superior completo. Das mães participantes deste estudo, quatro eram primíparas e duas tinham outro filho, além do bebê. Os bebês foram distribuídos igualmente quanto ao sexo. Segundo relato das mães, os bebês não apresentaram problemas de saúde e nasceram a termo (idade gestacional maior que 38 semanas).

\section{Instrumentos}

Para conhecer os comportamentos comunicativos intencionais dos bebês foram utilizados uma câmera de vídeo, cronômetro, lápis e papel.

\section{Procedimentos}

A pesquisa foi submetida ao Comitê de Ética do Centro de Ciências da Saúde da Universidade Federal da Paraíba (UFPB), obtendo aprovação através do protocolo de número 364/2006. No primeiro contato com as mães, foram explicitados os objetivos da pesquisa e solicitado o consentimento para a realização dos registros das interações com o uso do vídeo. A inclusão das mães no estudo foi condicionada à leitura e assinatura do Termo de consentimento e Livre Esclarecido.

As díades foram indicadas por pessoas que conheciam mães e bebês e que se adequavam aos critérios de inclusão da pesquisa, quais sejam: serem mães casadas, residentes em seus próprios domicílios, maiores de vinte anos e com o nível de instrução partindo do ensino médio completo. Além disso, os bebês deveriam não apresentar problemas no desenvolvimento. O primeiro contato com as mães foi feito por telefone e, uma vez concedida a permissão para a visita à casa da díade, marcou-se o contato pessoal com as mesmas. Nessa primeira 
visita, conforme disponibilidade da mãe e do bebê, era realizada a primeira das duas sessões de observação de cada idade. Antes de cada sessão de observação, foi solicitado às mães que "brincassem com seus filhos da maneira como faziam usualmente". Durante as sessões de observação estavam presentes apenas a pesquisadora, a mãe e o bebê visando evitar interrupções que poderiam alterar o curso das interações observadas.

As díades foram observadas duas vezes aos seis meses, aos nove meses e aos doze meses de idade do bebê, perfazendo um total de cento e vinte minutos de observação em cada díade. Cada sessão de observação teve a duração de vinte minutos, dos quais dez foram transcritos literalmente para análise.

\section{Análise dos Dados}

A análise dos dados nos três períodos buscou demonstrar os fluxos interativos característicos nas díades mãebebê em cada período evolutivo observado, a partir de uma leitura dinâmica e bidirecional dos comportamentos de ambos os membros da interação. Privilegiou-se uma leitura minuciosa dos tipos de interações que ocorreram em cada episódio, na perspectiva de captar suas características, verificar como se dava a participação de ambos os elementos da díade, as variações e modificações em cada idade subsequente nos diversos campos interativos estabelecidos. Nesta análise foram destacadas duas categorias gerais de habilidades sociocognitivas: os episódios interativos de atenção conjunta e suas derivações; e os atos comunicativos intencionais e/ou não intencionais das díades. Além disso, dados numéricos foram utilizados para embasar as análises referentes aos comportamentos de atenção conjunta no intuito de verificar as variações desses comportamentos em cada idade.

O critério utilizado para analisar as habilidades comunicativas intencionais dos bebês foi a evidência comportamental, que indicou se a criança teve uma intenção de comunicar algo em relação a um objeto ou ao parceiro (Rollins, 1999). Foi considerado um ato comunicativo o grupo de condutas não-verbais e/ou verbais produzidas por um emissor com a intenção de influenciar o comportamento e/ou o estado mental do outro (Rivero, 2003). De acordo com a literatura da área (Papaeliou \& Trevarthen, 2006; Striano \& Bertin, 2005; Tomasello, 2003), por volta do último trimestre do primeiro ano de vida, os bebês expressam, por meio de condutas, vocalizações e formas de interação com as mães, habilidades comunicativas intencionais que se caracterizam por comportamentos como: alternância de olhar entre a mãe e o objeto, seguido ou não por vocalização, apontar para objetos com alternância de olhar, vocalizar e alternar olhar, mostrar ou dar objetos a mãe, dentre outros comportamentos.

O processo de análise dos dados das interações videogravadas iniciou-se com as transcrições manuais de cada sessão; durante as transcrições, cada cena ou episódio foi revisto segundo a segundo com o intuito de registrar e descrever de forma minuciosa as seqüências interacionais de cada membro da díade. Numa segunda etapa, as sessões de cada díade, já transcritas, foram revistas para identificar trechos da interação em que pudessem ser observadas ações e vocalizações do bebê de natureza intencional e/ou não-intencional, estratégias sociocomunicativas e verbais maternas para envolvê-los na interação e os tipos de episódios interativos de atenção conjunta. Esses procedimentos permitiram identificar e caracterizar as principais modalidades sociocomunicativas dos bebês em cada período analisado. Na etapa seguinte, as categorias de análise foram formuladas baseando-se nos dados das interações registradas, nos objetivos da pesquisa e na literatura.

Optou-se por uma análise das interações que utilizou parte das classificações de atenção conjunta propostas por Tomasello (1995) e Tomasello, Carpenter, Call, Behne e Moll (2005), uma vez que isoladas as duas propostas de análise de contextos de atenção conjunta não foram consideradas satisfatórias para abarcar a natureza dos dados obtidos. Dessa forma, os resultados conduziram à proposta de incluir, como estrutura interativa de análise, as modalidades de atenção conjunta primária e não-atenção conjunta. Isto porque, percebeu-se nos contextos de não-atenção conjunta a ocorrência de atividades, nomeações, atribuições de significado aos comportamentos do bebê, bem como evidências de atos comunicativos do mesmo, intencionais ou não, que mobilizaram nas mães estratégias para chamar a atenção da criança e envolvê-la na interação.

Cabe mencionar que o tempo mínimo para se considerar um episódio interativo de atenção conjunta e suas diversas variações foi o de três segundos (Tomasello \& Todd, 1983). Em cada protocolo foi identificada a freqüência de ocorrência dos tipos de episódios interativos e suas possíveis variações entre as díades. O inicio de cada episódio interativo deu-se quando a mãe mostrou algo ao bebê ou chamou por ele, e ambos estabeleceram olhar mútuo ou olhar conjunto dirigido a um mesmo objeto, sendo o término identificado com a mudança da direção do olhar do bebê de um foco antes compartilhado, quando não houve uma resposta do bebê a um chamado da mãe, ou quando uma nova ação da mãe dirigida a um objeto diferente daquele para o qual o bebê estava olhando, provocava a "quebra" de um episódio.

Para verificar a fidedignidade da codificação dos episódios interativos e da participação dos membros da díade em cada período observado, $20 \%$ do material foram analisados por um segundo codificador para que fosse obtido o índice de concordância das categorias analisadas. A escolha dos protocolos para a análise do segundo codificador deu-se por sorteio, sendo codificados por aquele seis protocolos divididos igualmente por grupo de idade e sexo dos bebês. $\mathrm{O}$ cálculo de fidedignidade adotado foi realizado através da fórmula $\mathrm{IF}=(\Sigma \mathrm{A} / \Sigma$ (A+D) X 100), o qual é extraído por meio da somatória de concordância dividida pela somatória de concordância mais discordância entre observadores, vezes cem. As 
porcentagens de concordância do segundo codificador foram comparadas com as do codificador original. A partir dessa comparação, obteve-se $87 \%$ de concordância das categorias. As categorias de análise das habilidades comunicativas dos bebês e das mães estão dispostas em Anexo.

\section{Resultados e Discussão}

Os resultados dispostos na Figura 1 são derivados da análise dos protocolos de observação das interações mãe-bebê aos seis, nove e doze meses. Neste diagrama são expostas as diferentes configurações de atenção conjunta e as principais modalidades sociocomunicativas demonstradas pelos bebês em interação com as mães.

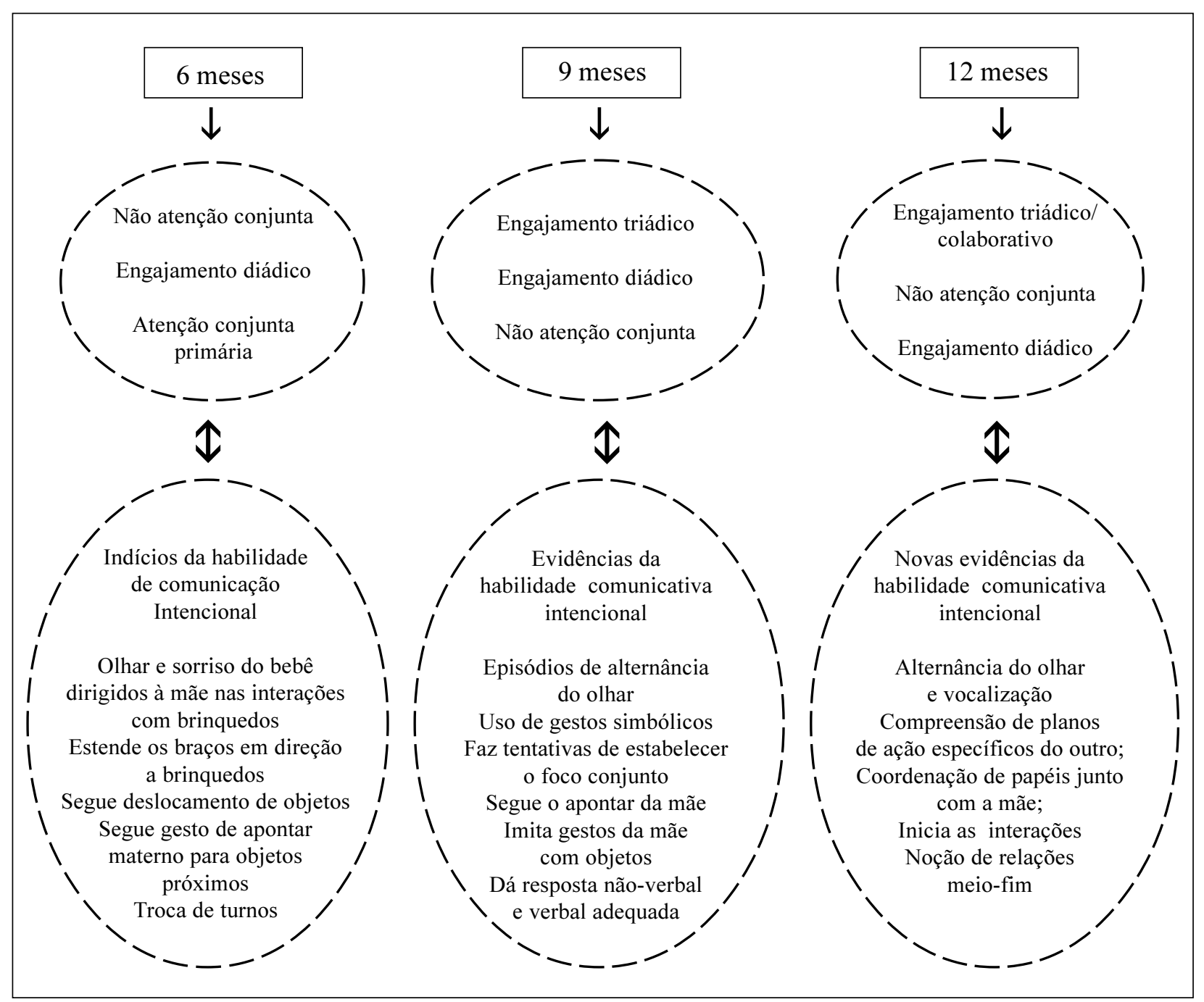

Figura 1. Diagrama das configurações de atenção conjunta e habilidades comunicativas intencionais das díades mãe-bebê, nos três períodos evolutivos estudados

Conforme sintetizado na Figura 1, os episódios interativos de atenção conjunta e as modalidades sociocomunicativas demonstradas pelos bebês nas três idades partiram de formas não intencionais de comunicação para modalidades comunicativas claramente intencionais, evidenciadas por suas condutas, vocalizações e formas de interação com as mães. Especificamente no que tange aos contextos de atenção conjunta e suas variações, foram observados diferentes arranjos interativos em torno dessa habilidade aos seis, nove e doze meses, conforme exibido no diagrama.
Observa-se que aos seis meses, embora não tenham sido encontradas evidências de comunicação intencional por parte dos bebês, foram observados comportamentos dos mesmos, os quais poderiam sugerir, em alguns recortes interativos, indícios da compreensão, por parte dos bebês, de que as mães estavam tentando chamar sua atenção para aspectos da interação. O conjunto de ações e respostas dos bebês às mães (olhar e sorriso do bebê dirigidos à mãe nas interações com brinquedos; extensão dos braços em direção a brinquedos; o comportamento de seguir o deslocamento de objetos, de seguir o gesto 
de apontar materno para objetos próximos e os episódios de troca de turnos) sua responsividade aos apelos e chamados maternos, em alguns trechos da interação, podem indicar que já nessa idade os bebês revelam indícios da habilidade de interpretar um ato comunicativo do adulto.

Verificou-se nas díades mãe-bebê, aos seis meses, uma maior ocorrência de episódios de não-atenção conjunta (58,3\%), quando comparados aos de atenção conjunta primária $(29,1 \%)$ cujas configurações incluíram, em alguns recortes, o engajamento diádico (12,6\%). Assinala-se que, nesses episódios, as trocas afetivas, as nomeações e atribuições de significado materno funcionaram como elementos imprescindíveis para envolver o bebê nas interações. Nesses contextos, as respostas dos bebês e seus "chamados" dirigidos às mães de forma não-verbal e verbal serviram como pistas para que as mães dessem continuidade às situações que emergiam do contexto de brincadeira. Nesses episódios foi possível demarcar ainda situações nas quais a mãe se utilizou de referência social apontando, demonstrando, aproximando, nomeando, dirigindo, reformulando, usando a fala em falsete, atribuindo significado às ações dos bebês, dentre outras modalidades comunicativas consideradas ações mediadoras que possibilitam a gradativa inserção dos bebês no mundo simbólico-cultural.

Considera-se pertinente relembrar a idéia de que as interações nesse período do desenvolvimento do bebê são extremamente breves e a atenção caracteriza-se pela quase simultaneidade do olhar entre o meio físico (brinquedos) e o social (mãe). Em relação a esse dado, deve-se assinalar que a percepção da atenção nos primeiros meses de vida está muito ligada ao aspecto emocional. Pesquisadoras como Reddy (2007) destacam que, no estudo da atenção conjunta, vários tipos de emoção e manifestações de afeto como o toque e a entonação da voz de ambos os membros da díade podem ser decisivos para a manutenção de um engajamento mútuo durante o curso de uma atividade.

Sobre esse aspecto, concorda-se com Rivero (2003), quando afirma que nas situações de atividade conjunta entre o adulto e o bebê, ambos os participantes têm representações diferentes da atividade na qual estão envolvidos, mas compartilham, em certo nível, a situação de interação. Existe entre eles um nível de intersubjetividade que em alguns casos torna desnecessário o olhar para o adulto. Essa afirmação é pertinente quando se analisam episódios de não-atenção conjunta, pois possibilita uma leitura mais abrangente dos diversos contextos interativos estabelecidos durante trocas mãe-bebê trazendo para a discussão a idéia de que a relação entre atenção conjunta e a comunicação intencional deve abarcar critérios para além do foco conjuntamente compartilhado. Já autores como Reddy (2007) acrescentam que "antes de o terceiro elemento" ser incorporado a uma relação diádica, mesmo na atenção mútua, a intencionalidade do outro já dis- puta um papel importante na consciência psicológica e no desenvolvimento infantil.

Nas interações mãe-bebê aos nove e aos doze meses, os episódios de não-atenção conjunta tiveram uma configuração diferente. As habilidades comunicativas intencionais já evidenciadas nos bebês, tais como responder verbalmente e não-verbalmente à mãe de forma correta, apontar, usar gestos simbólicos, seguir o olhar da mãe, iniciar interações, dar e oferecer brinquedos, dentre outros, ocorreram também num contexto de não-atenção conjunta, no qual a mãe e o bebê realizavam diferentes atividades ou manuseavam objetos isoladamente.

Aos nove e doze meses, é possível que os episódios de não-atenção conjunta tenham ocorrido em virtude do pouco interesse dos bebês por alguns brinquedos, por situações apresentadas pelas mães, pela aquisição de uma motricidade mais sofisticada que possibilitava aos bebês, principalmente aos doze meses, locomover-se para diversos espaços do ambiente se distanciando de suas mães. Além disso, aos doze meses, esses episódios podem ter ocorrido pela qualidade da responsividade materna aos comportamentos e iniciativas do bebê durante a situação de brincadeira.

Destacam-se nos bebês de nove meses modificações no tipo ou qualidade de atenção conjunta com a emergência de interações com engajamento triádico. Esse tipo de episódio foi mais freqüente $(48,57 \%)$, quando comparado aos episódios de não-atenção conjunta $(45,40 \%)$ e aos de engajamento diádico $(6,03 \%)$, os quais entrecortaram os episódios de atenção e não-atenção conjunta. Nessa idade foram observadas outras habilidades comunicativas tais como alternar o olhar entre a mãe e um objeto com o qual ambos se envolveram; imitar a ação de bater palmas após ter visto a mãe produzir esse ato; bater palmas espontaneamente e olhar para a mãe; pegar um brinquedo da mão da mãe e vocalizar; olhar para a mãe e vocalizar, e dar respostas não-verbais adequadas após solicitações da mãe. Essas habilidades mobilizaram nas mães modalidades comunicativas e verbais ajustadas às formas demonstradas, pelo bebê, de agir sobre as situações.

Aos doze meses pôde-se identificar comportamentos e tipos de interação que sugerem a aquisição por parte do bebê de uma forma mais complexa de atenção conjunta alternância do olhar e vocalização; compreensão de planos de ação específicos do outro; coordenação de papéis junto com a mãe; iniciativa nas interações; ações que denotavam a noção de relações meio-fim. Essas habilidades caracterizam o que Tomasello et al. (2005) designaram engajamento colaborativo.

Um dado importante a ser destacado refere-se aos trechos nos quais os bebês aos nove e doze meses iniciaram uma interação, ou buscaram redirecionar intencionalmente a atenção da mãe para eles por meio de gestos e vocalização. Em outras palavras, o bebê dirigia-se a sua mãe de forma comunicativa intencional também em epi- 
sódios em que não se evidenciava o estabelecimento de uma atenção conjunta entre os elementos da díade. Dados como esses podem exemplificar a complexidade do fenômeno da atenção conjunta e uma gama de variáveis implicadas no seu estudo. Isto porque durante o processo de análise dos dados surgiram questionamentos em torno das delimitações possíveis e dos critérios a serem utilizados para caracterizar cada episódio interativo estudado, e de que forma a intencionalidade comunicativa se manifestava nos bebês em cada idade.
A variedade de comportamentos e atos sociocomunicativos dos bebês nas interações observadas possibilitou ainda a elaboração de um gráfico evolutivo no qual foram expostas as principais características e habilidades dos bebês em cada idade. Os dados reunidos foram sintetizados tanto quanto possível, na tentativa de demonstrar as diferentes configurações e manifestações dos atos sociocomunicativos dos bebês nas três idades, coordenados com os contextos de troca estabelecida com as mães. As principais habilidades dos bebês aos seis, nove e doze meses estão dispostas abaixo.

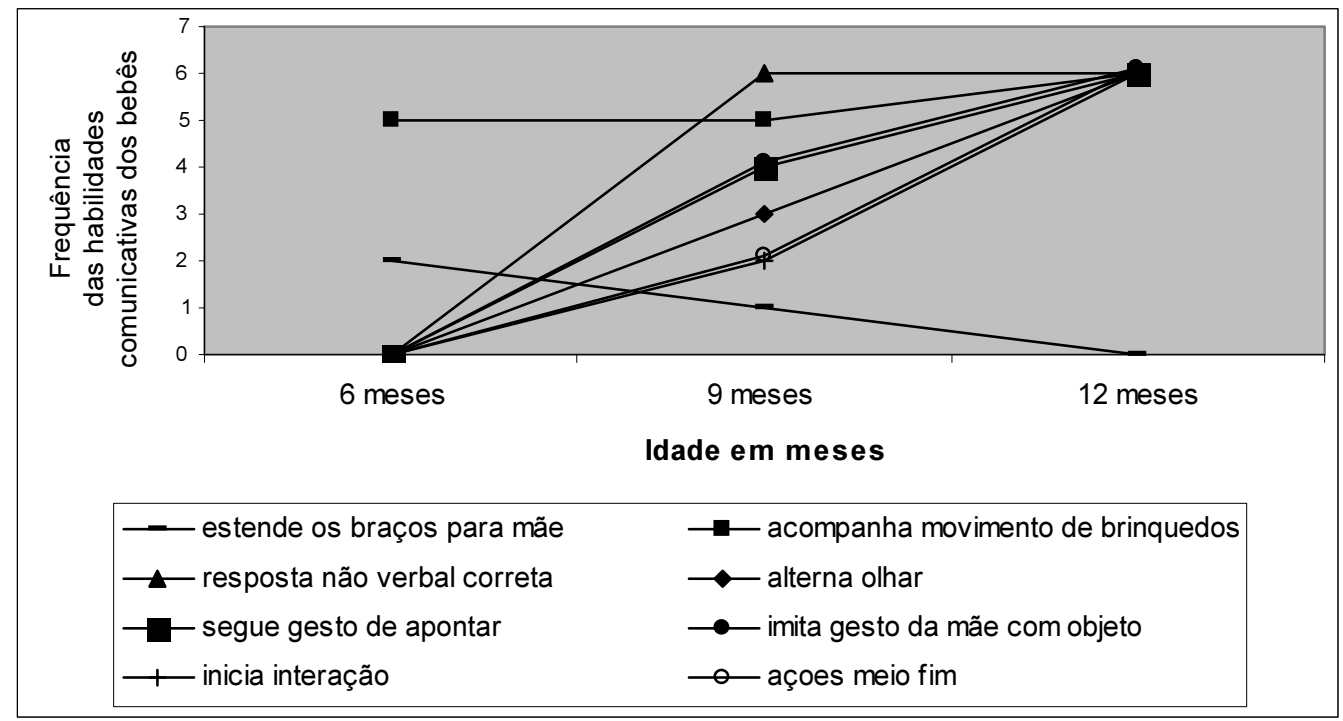

Figura 1. Diagrama das configurações de atenção conjunta e habilidades comunicativas intencionais das díades mãe-bebê, nos três períodos evolutivos estudados

A Figura 2 traça a curva de aquisições de alguns dos principais atos sociocomunicativos dos bebês identificados nas diferentes idades. Observa-se nos bebês aos seis meses o comportamento de estender os braços para a mãe, considerado por autores como Tomasello (1998) um gesto ritualístico, que, segundo ele, deflagra na mãe o quase imediato comportamento de pegar o bebê em seus braços. O uso desse gesto por parte dos bebês decresce, e não mais foi observado aos doze meses, provavelmente devido aos novos recursos comunicativos intencionais adquiridos pelos bebês aos doze meses, principalmente a aquisição de vocalizações.

Também deve ser assinalado que, embora tenha sido observada, aos seis meses, a habilidade de acompanhar o deslocamento de objetos, fundamental para o estabelecimento de interações com atenção conjunta, não foram identificados recortes interativos que evidenciassem habilidades comunicativas intencionais como: alternância do olhar entre o objeto e a mãe, o comportamento espontâneo do bebê iniciando interações, seguir o gesto de apontar, da mãe, e ações que denotassem a noção, por parte do bebê, da relação meio-fim de uma ação.

Uma análise minuciosa dos protocolos de observação permitiu verificar a ocorrência nessa idade de alguns dos comportamentos fundamentais para a aquisição da habilidade de atenção conjunta, tais como olhar para objetos mostrados pelas mães, e seguir o gesto de apontar, da mãe, para objetos próximos ao campo visual do bebê. Destaca-se, nesse grupo, a ocorrência de comportamentos no bebê como vocalizar enquanto olha e manuseia os brinquedos; e trechos em que o bebê sorri quando a mãe lhe mostra um brinquedo ou lhe dá voz, usando uma entonação em falsete. Esses comportamentos foram, em geral, bastante típicos entre os bebês dessa idade.

É importante mencionar que o comportamento de seguir o deslocamento de objetos foi observado, entre os bebês nas três idades, e que o mesmo constitui uma habilidade basilar para o estabelecimento de episódios de atenção conjunta. A alternância do olhar, por parte do bebê, sofreu modificações e se sofisticou em cada novo recorte evolutivo, demonstrando que as habilidades de atenção conjunta emergem de forma gradual, e não abrupta. Aos nove e aos doze meses esse comportamento passa a ser acompanhado pelo ato de alternar o olhar entre o objeto e a mãe, de seguir o apontar da mãe e de respostas não-verbais adequadas, comportamentos relatados pela literatura como observados em bebês nessas idades (Eilan, 2007; Franco, 2007; Hobson, 2007; Tomasello \& Carpenter, 2007). 
Já aos doze meses, principalmente, os bebês evidenciaram modalidades comunicativas e sociocognitivas tais como iniciar interações com a mãe, realizar ações que evidenciam a noção meio-fim e imitação da mãe com objetos, consideradas por pesquisadores (Franco, 2007; Tomasello et al., 2005; Woodward, 2007) como uma forma mais complexa de se comunicar com os parceiros sociais, já que sugere a habilidade, do bebê, de compartilhar planos ou metas do outro durante suas interações.

Além disso, deve-se mencionar que a aquisição da habilidade de imitar os gestos da mãe com objetos é uma forma de aprendizagem cultural que se reflete pela reprodução, por parte dos bebês, de ações intencionais do adulto sobre objetos externos. Tomasello (2003) adverte que esse tipo de imitação freqüentemente ocorre quando os adultos demonstram ou compartilham atividades com os bebês.

A leitura minuciosa dos dados obtidos em cada período observado permitiu demonstrar uma intricada dinâmica estabelecida entre atenção conjunta e dimensão intencional comunicativa. A relação entre esses dois aspectos da cognição social infantil foi evidenciada nas interações mãe-bebê aos nove e principalmente aos doze meses. A apreensão desses episódios em cada idade exigiu, além de considerar a habilidade do bebê de focar conjuntamente num mesmo objeto, analisar as atividades propostas pelas mães, a responsividade materna aos comportamentos e iniciativas dos bebês durante as interações, as formas de envolvimento do bebê em cada recorte interativo e os contextos específicos de trocas que emergiram da situação de brincadeira livre.

\section{Considerações Finais}

Os dados obtidos sobre os episódios de interação estudados e das modalidades sociocomunicativas demonstradas pelos bebês nas três idades pesquisadas permitem afirmar que os bebês evidenciaram habilidades comunicativas que partiram de formas não intencionais de comunicação para modalidades comunicativas claramente intencionais, expressas por suas condutas, vocalizações e formas de interação com as mães.

A análise dessas interações permitiu desenvolver a compreensão de que a habilidade de atenção conjunta de bebês, no primeiro ano de vida, engloba, além da habilidade de focar conjuntamente um mesmo objeto que o parceiro da interação, o aspecto maturacional da função psicológica 'atenção', os estilos comunicativos maternos, a responsividade das mães aos comportamentos e iniciativas dos bebês durante as interações, os contextos reais e cotidianos nos quais estão situadas as díades, e características dos próprios bebês durante as interações, que, ao se entrecruzarem, engendram diferentes cenários interativos.

Destaca-se a importância de evidências empíricas apresentadas neste estudo, obtidas por meio da observação e análise das interações. Assinala-se que a com- preensão do fenômeno da atenção conjunta e sua relação com a comunicação intencional deve ressaltar as nuances e transitoriedades de cada episódio interativo presente nas interações entre mães e bebês. Entende-se que a habilidade de atenção conjunta serve de lastro para o desenvolvimento sociocomunicativo e tem relações muito estreitas com a habilidade tipicamente humana da intencionalidade comunicativa e compartilhada. Pontua-se que a habilidade comunicativa intencional se desenvolve gradativamente nos bebês e é constituída a partir do imbricamento de diversas dimensões do desenvolvimento.

Nessa direção, reafirma-se que a relação entre atenção conjunta e as trocas intersubjetivas estabelecidas entre bebês e seus cuidadores primários é um dos aspectos que revela nos humanos uma singularidade relacional e um mergulho quase instantâneo destes no mundo cultural e simbólico desde muito precocemente. Considera-se pertinente a continuidade de pesquisas relativas à atenção conjunta, dentre outras razões, pelos possíveis esclarecimentos que tais estudos podem trazer para a explicação de prejuízos na comunicação e na linguagem.

A partir do conjunto de dados obtidos neste trabalho, destaca-se como imprescindível analisar de forma mais detalhada a emergência de gestos comunicativos intencionais e suas diversas configurações, estudados de forma minuciosa por pesquisadores (Camaioni et al., 2003; Franco, 2007; Liszkowski, 2005; Volterra, Caselli, Capirci, \& Pizzuto, 2004; Woodward, 2007) enquanto fundamentais para a cognição social infantil e a aquisição da linguagem oral.

Estudos longitudinais que identifiquem o momento de emergência de gestos como o apontar e suas formas de manifestação anteriores ao ato de apontar intencional possibilitam aos pesquisadores demarcar seu percurso ontogenético e as possíveis variações no momento de sua emergência em bebês de diferentes níveis socioeconômicos. Diante do exposto, sugere-se que estudos futuros aprofundem essa análise no sentido de acompanhar e identificar a emergência desses comportamentos, os eventos ou estilos interativos que precipitam seu surgimento e ainda as aquisições gerais que ocorrem e auxiliam esse percurso, fundamentalmente pelas repercussões dessas habilidades para a cognição social infantil.

\section{Referências}

Bakeman, R., \& Adamson, L. B. (1984). Coordinating attention to people and objects in mother-infant and peer-infant interaction. Child Development, 55, 1278-1289.

Bosa, C. (2002). Atenção compartilhada e identificação precoce do autismo. Psicologia: Reflexão e Crítica, 15(1), 77-88.

Braz, F. de S., \& Salomão, N. M. R. (2002). Episódios de atenção conjunta em contextos de brincadeira livre. Interações, 7(14), 85-104.

Braz Aquino, F. de S., \& Salomão, N. M. (2005). Estilos diretivos maternos apresentados a meninos e meninas. Estudos de Psicologia (Natal), 10(2), 223-230. 
Brooks, R., \& Meltzoff, A. N. (2008). Infant gaze following and pointing predict accelerated vocabulary growth through two years of age: A longitudinal, growth curve modeling study. Journal of Child Language, 35, 207-220.

Bruner, J. S. (1975). From communication to language: A psychological perspective. Cognition, 3(3), 255-287.

Bruner, J. S. (1980). Early social interaction and language acquisition. In H. R. Schaffer (Ed.), Studies in mother-infant interaction (pp. 271-289). New York: Academic Press.

Bruner, J. S. (1999). Intentionality and interpretation. In P. D. Zelazo, J. W. Astington, \& D. R. Olson (Eds.), Developing theories of intention: Social undertanding and self-control (pp. 329-339). Mahwah, NJ: Lawrence Erlbaum.

Camaioni, L., Aureli, T., Bellagamba, F., \& Fogel, A. (2003). A longitudinal examination of the transition to symbolic communication in the second year of life. Infant and Child Development, 12, 1-26.

Dunham, P. J., \& Moore, C. (1995). Current themes in research on joint attention. In C. Moore \& P. J. Dunham (Eds.), Joint Attention: Its origins and role in development (pp. 15-28). Hillsdale, NJ: Lawrence Erlbaum.

Eilan, N. (2007). Joint attention, communication, and mind. In N. Eilan, C. Hoerl, T. MacCormack, \& J. Roessler (Eds.), Joint attention: Communication and other minds: Issues in philosophy and psychology (pp. 1-33). New York: Oxford.

Franco, F. (2007). Infant pointing: Harlequin, Servant of two masters. In N. Eilan, C. Hoerl, T. MacCormack, \& J. Roessler (Eds.), Joint attention: Communication and other minds: Issues in philosophy and psychology (pp. 129-164). New York: Oxford.

Hobson, R. P. (2007). What puts the jointness into joint attention? In N. Eilan, C. Hoerl, T. MacCormack, \& J. Roessler (Eds.), Joint attention: Communication and other minds: Issues in philosophy and psychology (pp. 185-204). New York: Oxford.

Lampreia, C. (2007). A perspectiva desenvolvimentista para a intervenção precoce no autismo. Estudos de Psicologia (Campinas), 24(1), 105-114.

Lavelli, M., Pantoja, A. P. F., Hsu, H., Messinger, D., \& Fogel, A. (2004). Using microgenetic designs to study change processes. In D. M. Teti (Ed.), Handbook of research methods in delopmental science (pp. 4-65). New York: Blackwell.

Liszkowski, U. (2005). Human twelve-months-olds point cooperatively to share interest with and helpfully provide information for a communicative partner. Gesture, 5(1/2), 135-154.

Papaeliou, C. F., \& Trevarthen, C. (2006). Prelinguistic pitch patterns expressing 'communication' and 'apprehension'. Journal of Child Language, 33, 163-178.

Reddy, V. (2007). Before the "third element": Understanding attention to self. In N. Eilan, C. Hoerl, T. MacCormack, \& J. Roessler (Eds.), Joint attention: Communication and other minds: Issues in philosophy and psychology (pp. 85-109). New York: Oxford.

Rivero, M. (2003). Los inícios de la comunicación: la intencionalidad comunicativa y el significado como procesos graduales. Anuário de Psicologia, 34(3), 337-356.

Rochat, P. (2007). Intentional action arises from early reciprocal exchanges. Acta Psychologica, 124, 8-25.

Rollins, P. R. (1999). Early pragmatics accomplishments and vocabulary development in preschool children with autism. American Journal of Speech-Language Pathology, 8, 181-190.
Sabbagh, M. A., \& Baldwin, D. (2007). Understanding the role of communicative intentions in word learning. In N. Eilan, C. Hoerl, T. MacCormack, \& J. Roessler (Eds.), Joint attention: Communication and other minds: Issues in philosophy and psychology (pp. 165-184). New York: Oxford.

Santos, R. M., \& Braz Aquino, F. de S. (2003). Episódios de atenção conjunta num contexto de brinquedo livre: Um estudo transversal [Resumo]. In Sociedade Brasileira de Psicologia do Desenvolvimento (Ed.), Anais do IV Congresso Brasileiro de Psicologia do Desenvolvimento: Contextos de desenvolvimento, educação e cultura (pp. 245). João Pessoa, PB: Sociedade Brasileira de Psicologia do Desenvolvimento.

Sarriá, E. (1991). Observacion de la comunicacion intencional preverbal: um sistema de codificacion basado em el concepto de categoria natural. Psicotema, 3(2), 359-380.

Striano, T., \& Bertin, E. (2005). Social-cognitive skills between 5 and 10 months of age. British Journal of Development Psychology, 23, 1-11.

Tomasello, M. (1995). Joint attention as social cognition. In C. Moore \& P. J. Dunham (Eds.), Joint attention: Its origins and role in development (pp. 60-83). Hillsdale, NJ: Lawrence Erlbaum.

Tomasello, M. (1998). Reference: Intending that others jointly attend. Pragmatics \& Cognition, 6(1/2), 229-243.

Tomasello, M. (1999). Having intentions, understanding intentions, e understanding communicative intentions. In P. D. Zelazo, J. W. Astington, \& D. R. Olson (Eds.), Developing theories of intention: Social undertanding and self-control (pp. 64-75). Mahwah, NJ: Lawrence Erlbaum.

Tomasello, M. (2003). Origens culturais da aquisição do conhecimento humano: Tópicos (C. Berliner, Trad.). São Paulo, SP: Martins Fontes.

Tomasello, M., \& Carpenter, M. (2007). Shared intentionality. Development Science, 10(1), 121-125.

Tomasello, M., Carpenter, M., Call, J., Behne, T., \& Moll, H. (2005). Understanding and sharing intentions: The origins of cultural cognition. Behavioral and Brain Sciences, 28(5), 1-42.

Tomasello, M., \& Todd, J. (1983). Joint attention and lexical acquisition style. First Language, 4, 197-212.

Volterra, V., Caselli, M. C. Capirci, O., \& Pizzuto, E. (2004). Gesture and the emergence and development of language. In M. Tomasello \& D. Slobin (Eds.), Elizabeth Bates: A Festschrift. Mahwah, NJ: Lawrence Erlbaum.

Vygotsky, L. S. (1996). El primer año (L. Kuper, Trans.). In Obras Escogidas: Vol. IV. Psicología infantil (pp. 275-318). Madrid, España: Visor. (Original work published 1932)

Woodward, A. L. (2007). Infants' understanding of the actions involved in joint attention. In N. Eilan, C. Hoerl, T. MacCormack, \& J. Roessler (Eds.), Joint attention: Communication and other minds: Issues in philosophy and psychology (pp. 110-128). New York: Oxford.
Recebido: 01/06/2009 $1^{a}$ revisão: $20 / 10 / 2009$ Aceite final: 07/11/2009 
Aquino, F. S. B. \& Salomão, N. M. R. (2011). Intencionalidade Comunicativa e Atenção Conjunta: Uma Análise em Contextos Interativos Mãe-Bebê.

\section{Anexo}

\section{Categorias Gerais de Análise}

Estruturas Interativas de Atenção Conjunta

Atenção conjunta primária: evidencia-se a partir dos seis meses, quando o bebê olha para a mesma localização espacial do adulto, ou seja, quando ocorre o olhar simultâneo da díade para um mesmo objeto (Tomasello, 1995).

Engajamento diádico (face-a-face): interações nas quais se destacam o compartilhar de emoções, comportamentos e trocas de turnos em interações face-a-face nas quais os membros da díade são mutuamente responsivo um ao outro (Tomasello et al., 2005).

Engajamento triádico (por volta dos 9 aos 12 meses): episódios nos quais há o envolvimento do bebê e do adulto com um terceiro elemento para o qual ambos dirigem sua atenção e ações. Durante esses episódios, o olhar da criança deve estar coordenado com o do adulto para o objeto e/ou atividade que compartilham. Esse tipo de estrutura interativa ocorre entre 9 e 12 meses de vida dos bebês (Tomasello et al., 2005).

Engajamento colaborativo (a partir dos 12 meses): a criança compreende planos de ação específicos do outro, coordena papéis junto com a mãe, e inicia as primeiras tentativas de estabelecer ativamente uma atenção conjunta (Tomasello et al., 2005).

Não-atenção conjunta: episódios nos quais não há um foco conjunto da díade explicitamente dirigido a um determinado objeto, evento ou ao parceiro da interação.

Habilidades de Comunicação Intencional dos Bebês: (a) Olhar para a mãe (Papaeliou \& Trevarthen, 2006); (b) Pegar objetos oferecidos pela mãe (Papaeliou \& Trevarthen, 2006); (c) Estender os braços e tronco em direção a algo na presença do outro (Sarriá, 1991); (d) Mostrar um objeto (Papaeliou \& Trevarthen, 2006); (e) Dar objetos espontaneamente (Papaeliou \& Trevarthen, 2006); (f) Afastar com a mão um objeto ou parte do corpo do outro, esquivando-se (Sarriá, 1991); (g) Completar ações da mãe (Papaeliou \& Trevarthen, 2006); (h) Obedecer um comando da mãe (Papaeliou \& Trevarthen, 2006); (i) Apontar: estender o dedo indicador em direção a algum objeto, à mãe ou local do ambiente (Papaeliou \& Trevarthen, 2006); (j) Tarefa meio-fim: o bebê age como se formulasse "meios" de obter um determinado "fim" (Tomasello, 2003); (k) Uso de gestos simbólicos: derivados de uma aprendizagem de formas convencionais de interação (Camaioni et al., 2003); (1) Vocalizações (Papaeliou \& Trevarthen, 2006); (m) onomatopéias dirigidos à mãe alternadas com o olhar para ela (Sarriá, 1991). 